\title{
Lack of correlation between colony morphology and lipooligosaccharide content in the Mycobacterium tuberculosis complex
}

\author{
ANNe Lemassu, ${ }^{1}$ VÉRONIQue VinCENT LÉVy-Frébault, ${ }^{2}$ Marie-ANTOINETte Lanéelle ${ }^{1}$ and \\ MAMADOU DAFFÉ ${ }^{*}$ \\ ${ }^{1}$ Centre de recherche de Biochimie et Génétique Cellulaires du CNRS, 118 route de Narbonne, 31062 Toulouse cédex, \\ France \\ ${ }^{2}$ Unité de la tuberculose et des mycobactéries, Institut Pasteur 25, rue du Docteur Roux, 75724 Paris cédex 15, France
}

(Received 2 December 1991; revised 24 February 1992; accepted 5 March 1992)

\begin{abstract}
Rough and smooth colony variants of the Mycobacterium tuberculosis complex were compared with respect to their composition in trehalose-containing glycolipid antigens in view of the results of a recent investigation suggesting that the chemical basis of rough and smooth colony morphology in mycobacteria may reside in the occurrence of lipooligosaccharides. A careful chemical characterization of the individual glycolipids of the selected strains allowed the identification of the major glycolipids. The comparative study of the glycolipid content of the smooth Canetti strain, its spontaneous rough variant, and 16 additional strains of $M$. tuberculosis, $M$. bovis and $M$. africanum showed that the presence of lipooligosaccharides was not related to the morphology of the colonies.
\end{abstract}

\section{Introduction}

Mycobacterium tuberculosis is by far the most important of the mycobacterial pathogens and the one that has been responsible over the centuries for most of the mycobacteria-caused morbidity and mortality among human beings (Youmans, 1979). Consequently, notable efforts have been devoted to the tuberculosis elimination programme, which includes the early detection of the disease. In this respect, species or type-species-specific glycolipid antigens of $M$. tuberculosis have been chemically and serologically characterized (Cruaud et al., 1989, 1990; Daffé et al., 1987, 1989, 1991 $a, b$; Lemassu et al., 1991; Martin-Casabona et al., 1989; Papa et al., 1989a, $b$; Torgal Garcia et al., 1988, 1989). The most antigenic of these (Daffe et al., 1991b) belongs to the newest class of alkali-labile and phosphorus-free neutral glycolipids based on glycosidically linked acyl trehalose, the socalled lipooligosaccharides (LOS) (McNeil et al., 1989). The highly antigenic LOS described in $M$. tuberculosis strain Canetti (Daffé et al., 1991b) consisted of a lipononasaccharide with its own unique acyl amino epitope and a distinctive 6-O-methyl triacyl trehalose

\footnotetext{
* Author for correspondence. Tel. 613359 16; fax 61335886 .

Abbreviations: DAT, 2,3-diacyl trehalose; GPL, glycopeptidolipids; LOS, lipooligosaccharides; MMT, monomycoloyl trehalose; PGL, phenolic glycolipids.
}

unit. This antigen was found typifying the relatively smooth Canetti strain but was not detected in two typical rough strains of $M$. tuberculosis, namely $\mathrm{H}_{37} \mathrm{Ra}$ and $\mathrm{H}_{37} \mathrm{Rv}$ (Daffé et al., 1991 b). Interestingly, LOS have been characterized in three smooth variants of $M$. kansasii whereas the two examined rough strains of this species were devoid of the antigens (Belisle \& Brennan, 1989). In view of these preliminary indications, the present study was undertaken in order to ascertain the possible correlation between the occurrence of LOS and the morphology of the colonies in the $M$. tuberculosis complex. Eighteen strains, including the smooth colonyforming Canetti strain and its spontaneous rough mutant were examined for their glycolipid content and the smoothness and roughness of their colonies. The purpose of using rough and smooth colony-forming strains derived from the Canetti strain was to have isogenic strains to test the relationship between colony morphology and glycolipid composition.

\section{Methods}


appeared spontaneously from the smooth Canetti strain was picked directly from the plate and then subcultured on Middlebrook $7 \mathrm{H} 10$ agar plates to establish stability of its colony morphology.

Extraction and purification of glycolipids. Bacteria harvested from surface pellicles were extracted with $\mathrm{CHCl}_{3} / \mathrm{CH}_{3} \mathrm{OH}(1: 1, \mathrm{v} / \mathrm{v})$ at room temperature for 1 week; the bacterial residues were then re-extracted twice for $2 \mathrm{~d}$ with the same solvent mixture.

Pooled extracts were dried and then partitioned using $\mathrm{CHCl}_{3} / \mathrm{H}_{2} \mathrm{O}$ $(1: 1, \mathrm{v} / \mathrm{v})$; the lower $\mathrm{CHCl}_{3}$ phases were dried and the resulting washed lipids were dissolved in $\mathrm{CHCl}_{3}(5 \mathrm{ml})$ and applied to either a silicic acid column $(55 \times 2.1 \mathrm{~cm})$ or to a diethylaminoethyl (DEAE) cellulose column $(58 \times 2.5 \mathrm{~cm})$. The columns were successively eluted with $100 \mathrm{ml} \mathrm{CHCl}_{3}, \mathrm{CHCl}_{3} / \mathrm{CH}_{3} \mathrm{OH}(9: 1,8: 2,7: 3,1: 1, \mathrm{v} / \mathrm{v})$ and then with $100 \mathrm{ml} \mathrm{CHCl} / \mathrm{CH}_{3} \mathrm{OH} / \mathrm{H}_{2} \mathrm{O}(65: 25: 4$, by vol). For the DEAE column, further elutions were done with $100 \mathrm{ml} \mathrm{CHCl} / \mathrm{CH}_{3} \mathrm{OH}(4: 1$, $\mathrm{v} / \mathrm{v})$ containing $\mathrm{NH}_{4} \mathrm{OH}(2 \%, \mathrm{w} / \mathrm{v})$ and $\mathrm{CH}_{3} \mathrm{COONH}_{4}(0.01 \mathrm{M})$. The collected fractions $(100 \mathrm{ml}$ each) were dried and analysed by TLC.

Purified glycolipids were obtained by re-applying crude glycolipid fractions in $\mathrm{CHCl}_{3}(2 \mathrm{ml})$ to a silicic acid column $(50 \times 1.2 \mathrm{~cm})$ and eluting with the same solvent mixtures $(10 \mathrm{ml}$ each). Final purification was achieved by reverse phase chromatography using C-18 Sep-pak cartridges (Waters).

Analytical chromatographic techniques. TLC of chromatographic fractions was performed on precoated TLC plates of silicagel 60 on aluminium sheets (layer thickness $0.2 \mathrm{~mm}, 20 \times 20 \mathrm{~cm}$, Merck).

Native glycolipids were separated in polar solvent mixtures: $\mathrm{CHCl}_{3} /$ $\mathrm{CH}_{3} \mathrm{OH}(9: 1,7: 3, \mathrm{v} / \mathrm{v}), \mathrm{CHCl}_{3} / \mathrm{CH}_{3} \mathrm{OH} / \mathrm{H}_{2} \mathrm{O}(30: 8: 1,30: 12: 1$ and $65: 25: 4$, by vol.). Glycolipids were detected by spraying with $0 \cdot 2 \%$ anthrone in concentrated $\mathrm{H}_{2} \mathrm{SO}_{4}$ followed by heating at $110^{\circ} \mathrm{C}$. The Dittmer-Lester reagent (Dittmer \& Lester, 1964) was used for revealing phosphorus-containing substances.

Fatty methyl esters were analysed using $\mathrm{CH}_{2} \mathrm{Cl}_{2}$ as previously described (Daffé et al., 1983).

GLC was performed using a Girdel chromatograph (model G-30) equipped with a $25 \mathrm{~m}$ capillary column $(0.22 \mathrm{~mm}$ i.d.) containing WCOT-OV1 $(0.3 \mu \mathrm{m}$ film thickness, Spiral, Dijon, France); fatty methyl esters were separated with a temperature gradient of 150 $290^{\circ} \mathrm{C}\left(2^{\circ} \mathrm{C} \mathrm{min}^{-1}\right)$ whereas acetate derivatives of methyl glycosides were analysed using a temperature gradient of $130-290^{\circ} \mathrm{C}\left(2^{\circ} \mathrm{C} \mathrm{min} \mathrm{mi}^{-1}\right)$.

Miscellaneous analytical techniques. Alkaline hydrolysis of glycolipids was performed as previously described (Daffé et al., 1983). The water soluble material was desalted by mixing with Dowex 50WX4 resin (Fluka AG, Switzerland) $\left(\mathrm{H}^{+}\right)$, filtered and dried.

Acid hydrolysis was performed with $1 \mathrm{M}-\mathrm{HCl}$ in $\mathrm{CH}_{3} \mathrm{OH}$ for $3 \mathrm{~h}$ at $80^{\circ} \mathrm{C}$. The solution was then evaporated under vacuum.

Sugars were analysed as their peracetyl derivatives obtained by an overnight reaction with acetic anhydride/pyridine $(1: 1, \mathrm{v} / \mathrm{v})$ at room temperature and as their trimethylsilyl derivatives (Sweeley et al., 1963).

NMR spectra were obtained in $\mathrm{CDCl}_{3} / \mathrm{CD}_{3} \mathrm{OD}(2: 1, \mathrm{v} / \mathrm{v})$ with a Brucker 200 instrument at $23^{\circ} \mathrm{C}$. IR spectra were recorded on a Perkin-Elmer instrument model FTIR.

Mass spectra were obtained by the electron-impact technique using a Varian MAT 311A spectrometer; an ionizing voltage of $70 \mathrm{eV}$ and a temperature range of $100-250^{\circ} \mathrm{C}$ were used as previously described (Daffé et al., 1984).

For radiolabelling experiments with ${ }^{35} \mathrm{~S}, 1 \mathrm{mCi}$ of $\mathrm{Na}_{2}\left[{ }^{35} \mathrm{~S}^{\mathrm{O}} \mathrm{O}_{4}\right.$ was added per litre of medium, the $\mathrm{SO}_{4}^{2-}$-content of the medium was lowered by replacing half of the $\mathrm{MgSO}_{4}$ by $\mathrm{MgCl}_{2}$ (Goren, 1970). Bacteria, appearing as veils of growth in the medium after 4 weeks of growth, were extracted and the lipid extract fractionated as described above. To locate the radioactivity on the TLC plates (Lemassu et al., 1991), an automatic TLC linear analyser Berthold LB 2832 was used.
Desulphation was performed as previously described (Daffé $e t$ al, 1989).

\section{Results}

\section{Isolation of rough and smooth colonies from the Canetti strain of $M$. tuberculosis}

From among the mass of smooth colonies on Middlebrook $7 \mathrm{H} 10$ agar plates that characterize the Canetti strain (Fig. $1 a$ ), a rough variety appeared spontaneously, a common occurrence reported in cultures of smooth colony-forming mycobacterial strains (Barrow \& Brennan, 1982; Fregman et al., 1962; Grange, 1973). Repeated subculturing of the rough variant resulted in a culture containing only rough colonies (Fig. $1 b$ ) whereas subcultures of smooth colonies failed to give smooth colonies solely. The mutation event which lead to the rough variety does not affect the biochemical characteristics of the strain (Table 1) suggesting that simple mutation events have occurred (Grange, 1973). Other strains of the tubercle bacillus were selected for the present study because of the morphology of their colonies and their biochemical features (Table 1).

\section{Chemical characterization of LOS and other trehalose- containing glycolipids}

Using the chemically defined lipoocta- (LOS-I), and lipononasaccharide (LOS-II) isolated from the Canetti strain (Daffé et al., 1991b) as TLC standards, several glycolipids of similar polarity were detected in the crude lipid extracts of the examined strains (Fig. 2a). The TLC patterns of the various strains looked very similar and no obvious difference was noted between the lipid content of the various strains, regardless of the morphology of the colonies they formed (Fig. 2a). In order to analyse the distribution of the LOS in the selected strains, attempts were made to fractionate the crude extracts. Because of the similar polarity of the glycolipids under study, ion exchange chromatography was first applied, instead of adsorption chromatography. Using a DEAE column, it was possible to distinguish neutral from acidic glycolipids (Fig. $2 b$ ). By this procedure, it appeared that some glycolipids having chromatographic behaviour similar to that of LOS were in fact acidic compounds. These acidic glycolipids either contained phosphorus or could be labelled with ${ }^{35} \mathrm{~S}$ and could also be desulphated suggesting that these acidic glycolipids were composed of phosphatidyl inositol mannosides and sulphatides.

To distinguish the multiglycosylated version of LOS from miscellaneous acyl trehaloses, the neutral glycolipids were further fractionated by chromatography on a 

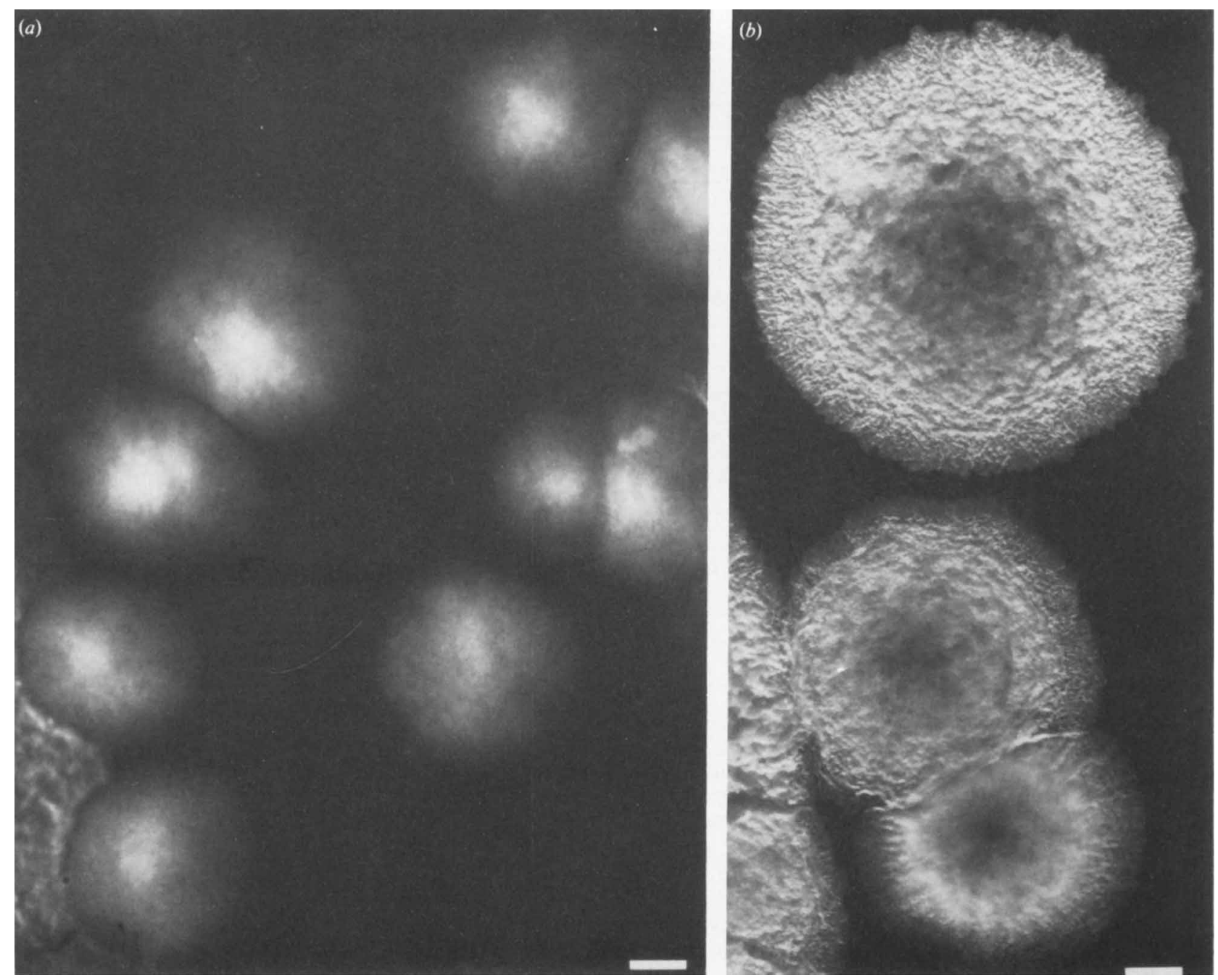

Fig. 1. Smooth colonies of $M$. tuberculosis strain Canetti (a) and rough colonies of its spontaneous mutant (b) on Middlebrook $7 \mathrm{H} 10$ agar plates. Bars, $1 \mathrm{~mm}$.

silicic acid column and the purified glycolipids were analysed by ${ }^{1} \mathrm{H}-\mathrm{NMR}$ and IR spectroscopy.

The least polar neutral glycolipid (Fig. $2 b$ ) was found to be identical to 6,6'-dimycoloyl trehalose ('cord factor') as it gave the same typical colour characteristic of this compound (Daffé et al., 1989) and had the same chromatographic behaviour in all the solvent mixtures used.

A more polar neutral glycolipid (Fig. $2 b$ ) gave spectra similar to those obtained previously for 2,3-diacyl trehalose (DAT) (Lemassu et al., 1991) and the fatty acyl substituents as well as the carbohydrate moiety were identified by GLC and were found to be identical to those of DAT. The compound with a slightly lower mobility than DAT (Fig. $2 b$, lanes 7 and 8) contained cyclopropane rings as deduced from its IR (absorption bands at $v 3060$ and $1020 \mathrm{~cm}^{-1}$ ) and NMR (signals at $\delta$ $0.3,0.1$ and 0.6 p.p.m.) spectra. Analysis of its constituents gave trehalose and mycolic acids identified by TLC and GLC, and by TLC and mass spectrometry (Daffé et al., 1983, Toubiana et al., 1979), respectively. By comparison with an authentic standard 6-mycoloyl trehalose sample, it was deduced that the glycolipid under study was a monomycoloyl trehalose (MMT). Two other more polar glycolipids (Fig. $2 b$ ), detected in the Canetti strain and another strain of $M$. tuberculosis forming smooth colonies (Table 1), were identified by TLC and GLC of their constituents as LOS-I and LOSII. The IR spectra of both purified LOS allowed the discrimination between the two glycolipids, i.e. LOS-II, but not LOS-I, exhibited the two characteristic absorption bands at 1690 and $1540 \mathrm{~cm}^{-1}$ consistent with the 
Table 1. Biochemical characteristics and distribution of trehalose-containing glycolipids in smooth $(S)$ and rough $(R)$ variants of $M$. tuberculosis, $M$. bovis and $M$. africanum.

\begin{tabular}{|c|c|c|c|c|c|c|c|c|c|c|c|}
\hline \multirow[b]{2}{*}{ Strain* } & \multirow[b]{2}{*}{ Morphology } & \multicolumn{7}{|c|}{ Biochemical tests $\dagger$} & \multicolumn{3}{|c|}{ Glycolipids $\ddagger$} \\
\hline & & Niacin & $\mathrm{TCH}$ & PZA & Pyr & Lebek & Glcase & Nit & DAT & MMT & LOS \\
\hline \multicolumn{12}{|l|}{ M. tuberculosis } \\
\hline CIPT 140010001 & $\mathbf{R}$ & + & + & - & - & - & + & + & + & + & - \\
\hline CIPT 140010045 & $\mathbf{R}$ & + & - & - & - & - & + & + & - & + & - \\
\hline CIPT 140010068 & $\mathbf{R}$ & + & - & - & & & - & + & + & + & - \\
\hline CIPT 140010071 & $\mathbf{R}$ & + & + & + & & & & & - & + & - \\
\hline CIP 88628 & $\mathbf{R}$ & + & - & - & & & & + & + & - & + \\
\hline CIPT 140010059 & $\mathbf{S}$ & - & + & - & - & - & + & + & + & - & + \\
\hline CIPT 140010059R & $\mathbf{R}$ & - & + & - & - & - & + & + & + & - & + \\
\hline CIPT 140010060 & $\mathbf{S}$ & - & + & - & - & - & + & + & + & - & + \\
\hline CIPT 140010061 & $\mathbf{S}$ & - & + & - & - & - & + & + & - & + & - \\
\hline CIPT 140010062 & $\mathbf{S}$ & - & + & - & - & - & + & + & - & + & - \\
\hline \multicolumn{12}{|l|}{ M. bovis } \\
\hline CIPT 140020001 & $\mathbf{S}$ & - & - & + & + & + & - & - & + & + & - \\
\hline CIPT 140020002 & $\mathbf{S}$ & - & - & + & + & & & - & + & + & - \\
\hline CIPT 140020005 & $\mathbf{R}$ & - & + & + & & & & + & - & + & - \\
\hline CIPT 140020010 & $\mathbf{R}$ & - & - & + & & & & - & + & + & - \\
\hline CIPT 140020011 & $\mathbf{R}$ & & - & + & & & & & - & + & - \\
\hline CIPT 140040001 & $\mathbf{R}$ & - & - & + & + & - & - & - & $\operatorname{tr}$ & + & - \\
\hline \multicolumn{12}{|l|}{ M. africanum } \\
\hline CIPT 140030001 & $\mathbf{S}$ & - & - & - & + & + & - & - & - & + & - \\
\hline CIPT 140030003 & $\mathbf{R}$ & + & + & - & & & - & + & + & + & - \\
\hline
\end{tabular}

* Strains CIPT 140010001, - 20001 and -30001 correspond to type strains of $M$. tuberculosis (ATCC 27294, $\mathrm{H}_{37} \mathrm{Rv}$ ), M. bovis (ATCC 19210) and M. africanum (ATCC 25420), respectively. The original Canetti strain is labelled CIPT 140010059 and Canetti-like strains are referred to as CIPT 140010060, -10061 and -10062 . The spontaneous rough variant of the Canetti strain is labelled CIPT 140010059R. Strain CIPT 140010045 was received from Dr Szabo (Budapest, Hungary) and strain CIPT 140040001 corresponds to BCG Pasteur. ATCC, American Type Culture Collection, Rockville, MD, USA; CIPT, Collection Institut Pasteur Tuberculose, Paris, France; CIP, Collection Institut Pasteur, Paris, France.

$\dagger$ Biochemical tests: Niacin, detection of niacin; TCH, growth in the presence of thiophencarboxylic acid hydrazide $(2 \mu \mathrm{g}$ $\left.\mathrm{ml}^{-1}\right)$; PZA, growth in the presence of pyrazinamid $\left(100 \mu \mathrm{g} \mathrm{ml}^{-1}\right)$; Pyr, stimulation of growth by pyruvate; Lebek, microaerophily; Glcase, detection of $\beta$-glucosidase; Nit, detection of nitrate reductase.

$\ddagger(+)$ indicates the detection of the glycolipids by TLC after fractionation of the crude lipid extracts by chromatography on a silicic acid column; tr, trace amounts.

presence of an aminosugar involved in the antigenicity of LOS-II (the characteristics of authentic LOS-I and -II had been established previously; Daffé et al., 1991 b). In a rough colony-forming $M$. tuberculosis strain (CIP 88628) a neutral glycolipid which had similar TLC and GLC properties as LOS-II was detected (data not shown). The purified glycolipid was shown to be a multiglycosylated lipooligosaccharide by NMR. Its glycosyl composition was found to consist of 2-Omethylfucose, 2-O-methyl rhamnose, rhamnose and glucose in a relation ratio $1: 1: 2: 1$. Hexa- and octadecanoic acids were the main fatty acids identified by GLC. It follows then that the glycolipid under study is a novel member of the LOS family.

\section{Distribution of the LOS in the M. tuberculosis complex}

LOS was detected in only a few strains of $M$. tuberculosis (Table 1). All the M. bovis and M. africanum strains were devoid of LOS regardless of the morphology of the colonies, demonstrating that this class of glycolipid antigens is not the main factor implicated in the morphology of the colonies. This conclusion was confirmed by the comparative analysis of the glycolipids of the original (smooth colony-forming) Canetti strain and its rough colony-forming variant (Fig. $2 b$, lanes 1-6). The compounds co-migrating with LOS (Fig. 2, lane 5) were isolated from the mutant strain and analysed. Their IR as well as their constituents, i.e. the sugar and fatty acid derivatives, were found to be identical to those of LOS of the Canetti strain (established previously; Daffé et al., $1991 b$ ). Incidentally, the phenolic glycolipids (PGL) previously characterized in the Canetti strain (Daffé, 1989; Daffé et al., 1987, 1988, 1991a) were found in its spontaneous mutant (data not shown). In addition to the two isogenic strains, LOS was characterized in only one smooth and one rough colony-forming strain of M. tuberculosis. Again, it was observed that two strains of 


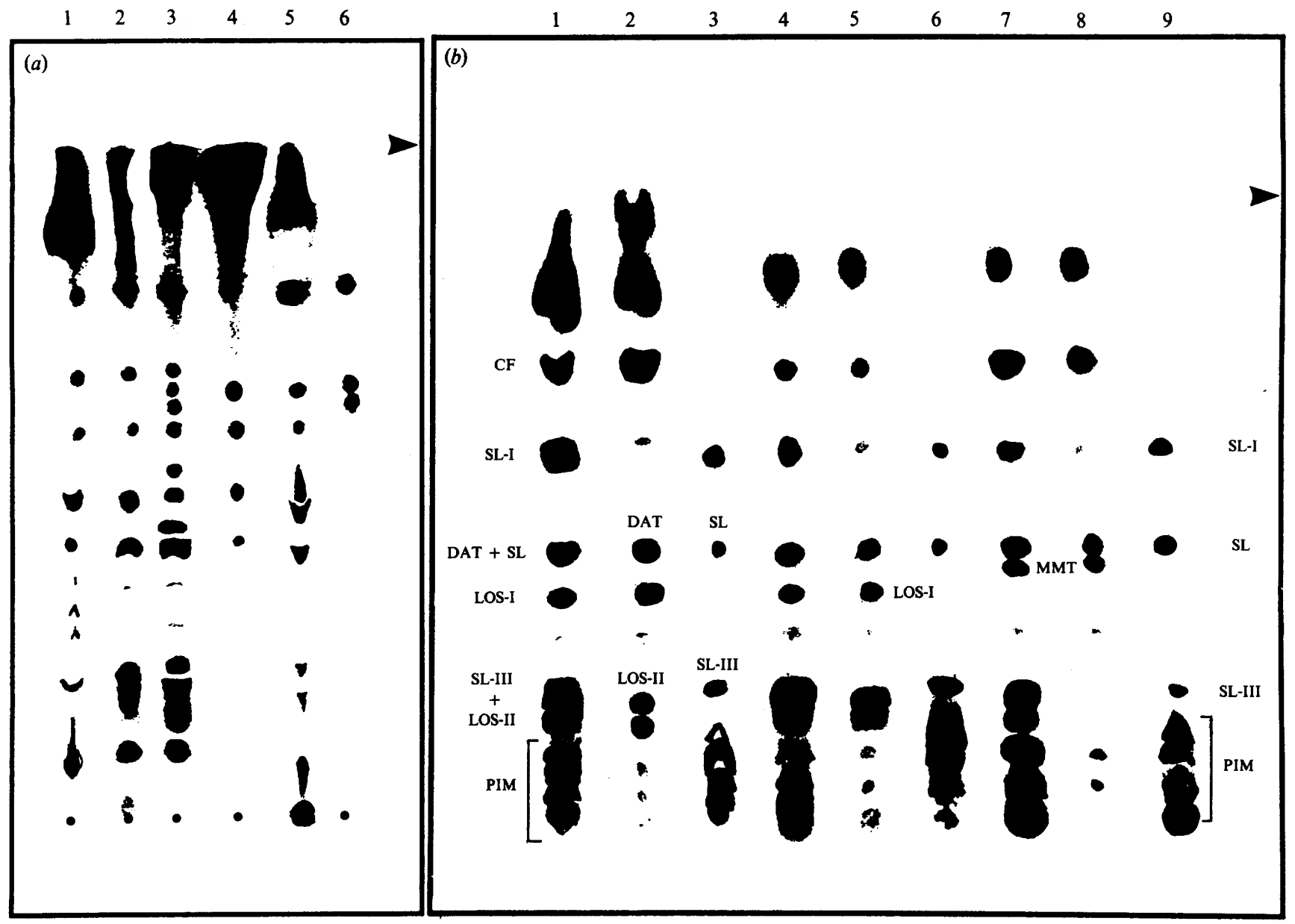

Fig. 2. (a) TLC of the unfractionated lipids of selected strains of $M$. tuberculosis. Lanes: 1 and 3, smooth colony-forming strains; 2,4 and 5, rough colony-forming strains; 6 , mixture of authentic standard samples of LOS-I and II isolated from the Canetti strain. Developing solvent: $\mathrm{CHCl}_{3} / \mathrm{CH}_{3} \mathrm{OH} / \mathrm{H}_{2} \mathrm{O}(60: 35: 8$, by vol.). (b) TLC of the crude lipid extracts of $M$. tuberculosis strain Canetti (lane 1), its spontaneous rough variant (lane 4) and $H 37 \operatorname{Rv}$ (lane 7). The corresponding neutral (lanes 2,5 and 8) and acidic (lanes 3,6 and 9) glycolipid-containing fractions eluted from DEAE columns with $\mathrm{CHCl}_{3} / \mathrm{CH}_{3} \mathrm{OH}(8: 2, \mathrm{v} / \mathrm{v})$ and with ammonium salt-containing solvents, respectively, are shown. Developing solvent: $\mathrm{CHCl}_{3} / \mathrm{CH}_{3} \mathrm{OH} / \mathrm{H}_{2} \mathrm{O}$ (30:12:1, by vol.). $\mathrm{CF}$, 'Cord factor' (6,6'-dimycoloyl trehalose); SL, sulphatides; PIMs, phosphatidylinositol mannosides. The arrowheads indicate the solvent fronts. The plates were sprayed with anthrone followed by heating at $110^{\circ} \mathrm{C}$ for $5 \mathrm{~min}$.

M. tuberculosis forming smooth colonies were devoid of LOS.

\section{Distribution of miscellaneous acyl trehaloses}

The acyl trehaloses (DAT or MMT) were more widely distributed in the tubercle bacilli than LOS (Table 1). DAT was detected and chemically characterized in some, but not all, strains examined herein (Table 1). MMT was detected in more strains of the $M$. tuberculosis complex than DAT (Table 1). However, the occurrence of both acyl trehaloses was not related to the morphology of the colonies. Similarly, 'cord factor' was detected in both smooth and rough colony-forming variants of the
Canetti strain (Fig. 2b), indicating that the presence of the ubiquitous glycolipid was not correlated with the smoothness and roughness of the tubercle bacillus colonies.

\section{Discussion}

The common objective of the earliest and the present-day investigations on mycobacterial lipids is the identification of specific components that might be implicated with the physiology of mycobacteria or biological events in the pathogenesis of diseases caused by these organisms. The dissociation of the tubercle bacilli into rough 
and smooth colonial forms offered the opportunity to correlate the virulence of the strains, the morphology of the colonies and chemically defined compounds (Long, 1958). The most notable of the earlier work, conducted by Cooper (1930), suggested that an avirulent rough variant of the tubercle bacillus (BCG) produced more lipid than the smooth virulent type dissociated from the same culture. Further studies correlated the presence of a class of surface antigens, the so-called glycopeptidolipids (GPL) (Barrow \& Brennan, 1982) or glycolipids (Fregman et al., 1962) to the smooth morphology of $M$. avium and $M$. intracellulare, and $M y$ cobacterium sp., respectively. With the finding of a spontaneous rough mutant that was identical to the parent smooth variant with respect to the GPL content (David et al., 1987), the correlation between the morphology of the colonies of $M$. avium and the presence of GPL was questioned. In the case of M. tuberculosis, GPL cannot be detected; instead, PGL (Daffé, 1989; Daffé et al., 1987, 1988, 1991a) and LOS (Daffé et al., 1991b) were characterized in some of the strains. Although the specific PGL of $M$. tuberculosis were originally isolated from a smooth variant (Daffé $e t$ al., 1987), their presence in other typical rough tubercle bacilli has since been demonstrated (Daffé et al., 1989, $1991 a$; Papa et al., 1989b). The spontaneous rough variant of the Canetti strain raised in this study also contains PGL, thus confirming that the occurrence of this class of glycolipid antigens is not related to the morphology of the tubercle bacilli. In contrast, LOS were found to occur on smooth variants of $M$. kansasii, but not in rough colony-forming strains (Belisle \& Brennan, 1989), again suggesting a correlation between this type of mycobacterial glycolipids and the morphology of the colonies. However, LOS in M. tuberculosis has recently been well characterized (Daffé et al., 1991b) and in this paper we show that both the rough and smooth isogenic variants of the Canetti strain contain this class of glycolipids. It remains possible that the quantity of LOS may affect colony morphology, but the absence of LOS in most strains of the $M$. tuberculosis complex examined, both rough and smooth colony-forming (see Table 1), clearly shows that this class of glycolipids is not the major factor affecting the morphology of these strains. In agreement with this finding is the observation that LOS are not major constituents of the smooth Canetti strain ( $2 \%$ of the crude lipid extract; Daffé et al., 1991b).

The morphology of mycobacterial colonies has also been often correlated to the pathogenicity of the strains (Cooper, 1930; Collins \& Cunningham, 1981 ; Schaefer $e t$ al., 1970). In the case of the tubercle bacillus, the dissociation of the human tubercle bacillus $\mathrm{H}_{37}$ into its extreme rough variants, virulent $(\mathrm{Rv})$ and avirulent $(\mathrm{Ra})$ (Dréa, 1953), shows that the earlier association between smooth and virulence on the one hand, and rough and avirulence on the other hand (Cooper, 1930), is not always reliable. The similar behaviour of the Canetti strain and $\mathrm{H}_{37} \mathrm{Rv}$ in experimental infections (Papa et al., $1989 b$ ) confirms the concept that both rough and smooth variants may be virulent strains.

Beside these observations, another conclusion can be drawn from our data. Through the characterization of the different glycolipids, it appeared that the unfractionated lipid extracts of the tubercle bacilli contain complex mixtures of various classes of glycolipids. This may lead to misinterpretations of both serologic and chemical data if further fractionation and characterization are not done. TLC alone may not be enough as we found acidic and neutral glycolipids as well as trehalose derivatives and multiglycosylated compounds had co-eluted.

This work was supported in part by a grant from the 'Fonds spécial des Comités départementaux contre les maladies respiratoires et la tuberculose' (contrat no. $90 \mathrm{~T} / 2$ ). The authors thank Mr E. Barbey for his help with photography and Dr Lanéelle for helpful discussions.

\section{References}

Barrow, W. W. \& BREnNAN, P. J. (1982). Isolation in high frequency of rough variants of Mycobacterium intracellulare lacking C-mycoside glycopeptidolipid antigens. Journal of Bacteriology 150, 381-384.

Belisle, J. T. \& BrenNan, P. J. (1989). Chemical basis of rough and smooth variation in mycobacteria. Journal of Bacteriology 171, 34653470 .

Collins, F. M. \& Cunningham, D. S. (1981). Systemic Mycobacterium kansasii infection and regulation of the alloantigenic response. Infection and Immunity 32, 614-624.

COOPER, F. B. (1930). Chemistry of the tubercle bacillus. I-Analysis of bacillus Calmette-Guerin (BCG). Journal of Biological Chemistry 88, 485-491.

Cruaud, P., Berlie, C., Torgal-Garcia, J., Papa, F. \& David, H. L. (1989). Human IgG antibodies immunoreacting with specific sulfolipids from Mycobacterium tuberculosis. Zentralblatt für Bakteriologie A 271, 481-485.

Cruaud, P., Yamashita, J. T., Martin Casabona, N., Papa, F. \& DAvID, H. L. (1990). Evaluation of a novel 2,3-diacyl trehalose 2' sulphate (SL-IV) antigen for case finding and diagnosis of leprosy and tuberculosis. Research in Microbiology 141, 679-694.

DAFF́, M. (1989). Further specific triglycosyl phenol phthiocerol diester from Mycobacterium tuberculosis. Biochimica et Biophysica Acta 1002, 257-260.

Daffé, M., Lanéelle, M.-A., Asselineau, C., Lévy-Frébault, V. \& DAVID, H. L. (1983). Intérêt taxonomique des acides gras des mycobactéries: proposition d'une méthode d'analyse. Annales de Microbiologie 134B, 241-256.

Daffé, M., Lanéelle, M.-A., Roussel, J. \& Asselineau, C. (1984). Lipides specifiques de Mycobacterium ulcerans. Annales de Microbiologie 135A, 191-201.

Daffé, M., lacave, C., Lanéelle, M.-A. \& Lanéelle, G. (1987). Structure of the major triglycosyl phenol phthiocerol of Mycobacterium tuberculosis (strain Canetti). European Journal of Biochemistry $167,155-160$.

Daffé, M., Lanéelle, M.-A., Lacave, C. \& Lanéelle, G. (1988). Monoglycosyl diacyl phenol phthiocerol of Mycobacterium tuberculosis and Mycobacterium bovis. Biochimica et Biophysica Acta 958, 443449 . 
Daffé, M., PaPa, F., Laszlo, A. \& David, H. L. (1989). Glycolipids of recent clinical isolates of Mycobacterium tuberculosis: chemical characterization and immunoreactivity. Journal of General Microbiology 135, 2759-2766.

Daffé, M., McNeil, M. \& Brennan, P. J. (1991b). Novel typespecific lipooligosaccharides from Mycobacterium tuberculosis. Biochemistry 30, 378-388.

Daffé, M., Cho, S.-N., Chatterjee, D. \& Brennan P. J. (1991a). Chemical synthesis and seroreactivity of a neoantigen containing the oligosaccharide hapten of the Mycobacterium tuberculosis-specific phenolic glycolipid. Journal of Infectious Diseases 163, 161-168.

David, H. L., Rastogi, N., Clavel-Sérès, S., Clément, F. \& Thorel, M.-F. (1987). Structure of the cell envelope of Mycobacterium avium. Zentralblatt für Bakteriologie 264, 49-66.

DitTMER, J. C. F. \& LeSTER, R. L. (1964). A simple specific spray for the detection of phospholipids on thin layer chromatograms. Journal of Lipid Research 5, 126-127.

DrÉA, W. F. (1953). Enzymes. In The metabolism of the Tubercle Bacillus, pp. 188-267. Edited by W. F. Dréa, A. Andrejew \& E. R. Long). Springfield: Thomas.

Fregman, G. B., SMith, D. W. \& Randall, H. M. (1962). A mutant of a scotochromogenic Mycobacterium detected by colony morphology and lipid studies. Journal of Bacteriology 83, 828.

Goren, M. B. (1970). Sulfolipid I of Mycobacterium tuberculosis, strain $\mathrm{H}_{3}$, Rv. I. Purification and properties. Biochimica et Biophysica Acta 120, 116-126.

GRANGE, J. M. (1973). Intra-specific variation in the mycobacteria: a taxonomic aid. Annales de la Societé Belge de Médecine Tropicale 53, $339-346$.

Lemassu, A., LANÉelle, M.-A. \& Daffé, M. (1991). Revised structure of a trehalose-containing immunoreactive glycolipid of Mycobacterium tuberculosis. FEMS Microbiology Letters, 78, 171-176.

LoNG, E. R. (1958). Chemical factors in virulence. In The Chemistry and Chemotherapy of Tuberculosis, pp. 43-51. Edited by E. R. Long. London: Bailliere, Tindall and Cox.

Martin-Casabona, N., GonZalez-Fluente, T., Arcalis-Arce, L., Otal-Entraigas, J. \& Vidal-Pla, R. (1989). Evaluation of a phenolglycolipid antigen (PGL-Tb1) from $M$. tuberculosis in the serodiagnostic of tuberculosis: comparison with PPD antigen. Acta Leprologica VII, supplement 1, 89-93.

McNeil, M., Chatterjee, D., Hunter, S. W. \& Brennan, P. J. (1989). Mycobacterial glycolipids: isolation, structures, antigenicity and synthesis of neoantigens. Methods in Enzymology 179, 215242.

Papa, F., Cruaud, P. \& David, H. L. (1989a). Antigenicity and specificity of selected glycolipid fractions from Mycobacterium tuberculosis. Research in Microbiology 140, 569-578.

Papa, F., Laszlo, A., David, H. L. \& DafFÉ, M. (1989b). Serological specificity of Mycobacterium tuberculosis glycolipids. Acta Leprologica VII, supplement 1, 98-101.

SaUton, B. (1912). Sur la nutrition minérale du bacille tuberculeux. Comptes Rendus de l'Académie des Sciences Serie III Sciences de la Vie 155, 860-863.

SCHAEFER, W. R., Davis, C. L. \& CoHN, M. L. (1970). Pathogenicity of transparent, opaque, and rough variants of Mycobacterium avium in chickens and mice. American Review of Respiratory Diseases 102, 499-506.

Sweeley, C. C., Bentley, R., Makita, M. \& Wells, W. W. (1963). Gas-liquid chromatography of trimethyl silyl derivatives of sugars and related substances. Journal of the American Chemical Society 85 , 2497-2507.

Torgal-Garcia, J., David, H. L. \& Papa, F. (1988). Preliminary evaluation of a Mycobacterium tuberculosis phenolglycolipid antigen in the serologic diagnosis of tuberculosis. Annales de Microbiologie 139, 289-294.

Torgal-Garcia, J., PaPa, F. \& David, H. L. (1989). Immunological response to homologous and heterologous phenolic glycolipid antigens in tuberculosis and leprosy. Acta Leprologica VII, supplement 1, 102-106.

Toubiana, R., Berlan, J., Sato, H. \& Strain, M. (1979). Three types of mycolic acid from Mycobacterium tuberculosis Brévanne: implications for structure-function relationships in pathogenesis. Journal of Bacteriology 139, 205-211.

Youmans, G. P. (1979). The morphology and metabolism of mycobacteria. In Tuberculosis, pp. 8-45. Edited by G. P. Youmans. Philadelphia, USA: W. B. Saunders. 